With 1 plate

Printed in Great Britain

\title{
The Nature and Radiation Sensitivity of the Long Forms of Escherichia coli Strain B/r
}

\author{
By R. J. MUNSON AND F. I. MACLEAN \\ Medical Research Council, Radiobiological Research Unit, \\ Harwell, Didcot, Berkshire
}

(Received 26 August 1960)

\begin{abstract}
SUMMARY
By suitable adjustment of growth conditions in continuous cultures, organisms of Escherichia coli $\mathrm{B} / \mathrm{r}$ with average lengths covering a wide range were produced and studied. From X-ray survival data it was concluded that radiosensitive sites were distributed along the length of an organism at intervals of 1-1.5 $\mu$, whilst nuclear staining by the $\mathrm{HCl}$-Giemsa method showed chromatinic bodies at an average spacing of $1.2 \mu$. Thus each nuclear body appeared to be a radiosensitive site. Lysozyme treatment did not reveal evidence of transverse membranes apart from those at visible 'waists'. It was concluded that the longer organisms arose by the inhibition of the terminal stages of division. This inhibition did not affect the multiplication of the nuclear and cytoplasmic components, although there was considerable aggregation of nuclear material in irradiated organisms.
\end{abstract}

\section{INTRODUCTION}

When Escherichia coli strain $\mathrm{B} / \mathrm{r}$ is cultivated in a glucose salts medium the average length of the organism ('cells' in sequel; see Maclean \& Munson, 1961) can be altered by changing the temperature and the population density and also by gamma irradiation (Maclean \& Munson, 1961). By adjustment of these environmental factors one could therefore readily compare the properties of $E$. coli strain B/r rods of different lengths, and investigate any specific effects associated with growth under gamma irradiation. From studies of $\mathbf{X}$-ray survival and of the number and disposition of nuclear bodies and cell membranes, some progress has been made towards an understanding of the nature of the long forms and the effect of radiation on their division processes.

\section{METHODS}

The present experiments were carried out with Escherichia coli strain B/r cultivated in a continuous system in a glucose salts medium as described earlier (Maclean \& Munson, 1961). Cultures were grown at $22^{\circ}$ and $37^{\circ}$ and in some experiments they were irradiated continuously with ${ }^{60} \mathrm{Co}$ gamma radiation at dose rates of $600 \mathrm{r}$. $/ \mathrm{hr}$. at $22^{\circ}$, and $1000 \mathrm{r}$. $/ \mathrm{hr}$. at $37^{\circ}$. Adjustment of the bacterial concentration (population density) provided a simple means of controlling the average length when the temperature and radiation dose-rate had been fixed. In each experiment growth was continued for at least 10 generation times under the selected conditions in order to allow the length distribution amongst the population to become stable. Samples were then drawn from the culture vessel with Pasteur 
pipettes, one to be $\mathrm{X}$-irradiated and the other for length measurements of 100 to 300 living cells. In some cases a third sample was taken for nuclear staining.

Survival after $X$-irradiation. The sample for $X$-irradiation was diluted to a population density of $10^{5} / \mathrm{ml}$. in ice-cold sterile minimal medium (Lederberg, 1950) prepared some hours previously. Samples of the suspension were put into small glass tubes cooled in ice and water, and exposed to X-ray doses of $0,2,5,10$ and $20 \mathrm{kr}$. delivered at a dose rate of $550 \mathrm{r}$. $/ \mathrm{min}$. The radiation half value layer was $1.2 \mathrm{~mm}$. copper. After irradiation $\mathbf{0} \cdot \mathbf{1} \mathrm{ml}$. samples were spread on minimal medium containing $2 \%(\mathrm{w} / \mathrm{v})$ agar. The plating was carried out at room temperature as rapidly as possible and incubation at $37^{\circ}$ was usually started within $30 \mathrm{~min}$. of the end of the irradiation. Final counts of colonies were made after incubation for $\mathbf{7 2} \mathrm{hr}$. Amongst cultures which were not exposed to $\mathrm{X}$-radiation the population of viable cells was not significantly less than unity $(0 \cdot 95 \pm 0 \cdot 21)$.

Although our procedure of plating at room temperature was convenient it was open to the objection that recovery or restoration during the interval before the cells reached $37^{\circ}$ might have altered the proportion of cells surviving and hence also the shapes of survival curves (Stapleton, Billen \& Hollaender, 1953; Alper \& Gillies, 1960). The ratio (colony count):(colony count at zero restoration time) which may be termed the restoration factor, was therefore measured at room temperature for restoration times up to $4 \mathrm{hr}$. The restoration factor increased progressively with dose of radiation and with restoration time up to about one generation time. There was, however, no evidence of a change in shape of survival curves, the smaller alterations in the surviving fractions after $30 \mathrm{~min}$. restoration being equivalent merely to an expansion of the dose scale by a few \%. We conclude that any errors in the estimation of surviving fractions due to partial restoration were of the same order as the overall errors due to other causes. No correction for restoration was therefore made.

Nuclear staining. Staining was carried out by a variation of the HCl-Giemsa method (Robinow, 1944). Smears were fixed in osmic acid vapour (3 min.), placed in Schaudinn's ethanol solution ( $1 \frac{1}{2} \mathrm{~min}$.) and stored overnight in iodine + ethanol. The following day the slide was placed in $\mathrm{N}-\mathrm{HCl}$ at $55^{\circ}-60^{\circ}(10 \mathrm{~min}$.), washed with M/400 phosphate buffer ( $\mathrm{pH} \mathrm{7 \cdot 0)}$, stained with Giemsa (37 for $4 \mathrm{hr}$.) and dried and mounted in Canada balsam.

Digestion of bacterial DNA with DNA-ase. Two bacterial smears were made on one slide and these were dried and fixed in acetic acid + ethanol $(1+3)$. On the following day a depression slide containing a solution of DNA-ase (DNA-ase, once recrystallized; Nutritional Biochemical Corpn.; $150 \mu \mathrm{g} . / \mathrm{ml}$.; $\mathrm{MgSO}_{4}, 1.75 \times 10^{-3} \mathrm{M}$ in 0.06 Mphosphate buffer, $\mathrm{pH} \mathrm{7 \cdot 2)}$ was mounted over one smear and over the other smear a similar depression slide without DNA-ase. The slides were sealed with paraffin and incubated at $37^{\circ}$ for $30 \mathrm{~min}$. The depression slides were then removed and staining continued as above. The DNA-ase activity was tested by the method of McDonald (1955). No RNA-ase was detected by a modification (Dr J. E. Stanier, personal communication) of the method of Bernheimer \& Steele (1955).

\section{Preparation of osmotically sensitive spheres}

Cell suspensions were filtered through a membrane filter (Oxoid) and washed with $\mathbf{1 0}^{-3} \mathrm{M}$-phosphate buffer $(\mathrm{pH} \mathrm{7 \cdot 0}$ ) and then with $0 \cdot 1 \mathrm{M}-2$-amino-2-hydroxymethyl- 
propane-1 : 3 diol (tris) buffer ( $\mathrm{pH} \mathrm{8 \cdot 0).} \mathrm{A} \mathrm{few} \mathrm{drops} \mathrm{of} \mathrm{a} \mathrm{solution} \mathrm{of} \mathrm{lysozyme} \mathrm{(100} \mu \mathrm{g}$. lysozyme/ml., Nutritional Biochemical Corpn., Cleveland, Ohio, U.S.A.; $200 \mu \mathrm{g}$. ethylenediaminetetra-acetic acid/ml., in $3 \times 10^{-2} \mathrm{M}$-tris buffer $(\mathrm{pH} \mathrm{8.0})$ and $\mathbf{0 . 5} \mathrm{M}$ sucrose; Mahler \& Fraser, 1956) was applied to the paper and the cells brought into suspension by stirring with a platinum loop. A few loopfuls were then used to fill a depression slide (100 $\mu$ deep), which was sealed with a coverslip and cedar wood oil. The progress of the action of the lysozyme was then followed microscopically and photographs taken of the spheroplasts which had settled to the bottom of the depression.

\section{RESULTS}

\section{Shapes of $X$-ray survival curves}

The proportion of cells able to form colonies on minimal agar after $\mathrm{X}$-irradiation was found to be a function of the dose of $\mathrm{X}$-radiation and the average cell length; some typical results are shown in Fig. 1, where the logarithm of the surviving fraction is plotted against the dose of $\mathrm{X}$-radiation. For the shortest cells the survival curve is almost exponential but as the average length increases the shoulders become more and more marked. By drawing smooth curves through the experimental points instead of the broken lines as in Fig. 1, the doses of X-radiation for any degree of survival (or killing) can be found. The shapes of the survival curves can then be conveniently specified in terms of the ratio of the $\mathbf{X}$-irradiation doses at two arbitrarily chosen degrees of killing. It appears from Fig. 2 that the ratio of the doses for 90 and $50 \%$ killing, namely, LD90/LD50, depended mainly upon the average cell length and was independent of the cultural conditions within the rather wide limits set by the scatter of the points.

The graphs of Fig. 1 are similar in form to the family of survival curves which can be derived theoretically on certain simple assumptions which are formally equivalent to those of Lea (1946) and Atwood \& Norman (1949). These assumptions are: (a) each cell consists of an integral number, $r$, of units which can be independently inactivated by radiation; $(b)$ the probability of inactivation of a unit is $\left(1-e^{-\lambda D}\right)$ where $\lambda$ is its radiosensitivity and $D$ is the radiation dose; $(c)$ a cell remains viable in the sense that it can give rise to a colony provided that one or more of its units are not inactivated.

Whatever the nature of the units, it can readily be shown that the fraction $S_{r}$ of cells with $r$ units/cell which survive a dose $D$ is given by

whence it follows that

$$
S_{r}=1-\left(1-e^{-\lambda D}\right)^{r},
$$

$$
\frac{\operatorname{LD90}}{\operatorname{LD50}}=\frac{\ln \left(1-\left(\frac{9}{10}\right)^{1 / r}\right)}{\ln \left(1-\left(\frac{5}{10}\right)^{1 / r}\right)} .
$$

Comparison of the calculated values of the ratio LD90/LD50 for different values of $r$, shown on the scale to the right of Fig. 2 with the observed ratio LD90/LD50 for cells of different average length, indicates that $r$ is approximately proportional to the average cell length. Thus $r=8$ corresponds to a length of $12 \mu, r=4$ to $6.5 \mu$, $r=2$ to $3 \cdot 5 \mu$, and $r=1$ to approximately $2 \mu$. The survival data are therefore consistent with our assumptions if the units of which a cell is composed each occupy on the average about 1.5 $\mu$ of its length. Since it has been assumed that a colony 
can arise from only one unit, each unit must contain one nucleus at least. It seems therefore likely that stained nuclei may prove to be useful markers of the assumed functionally separate cellular units.

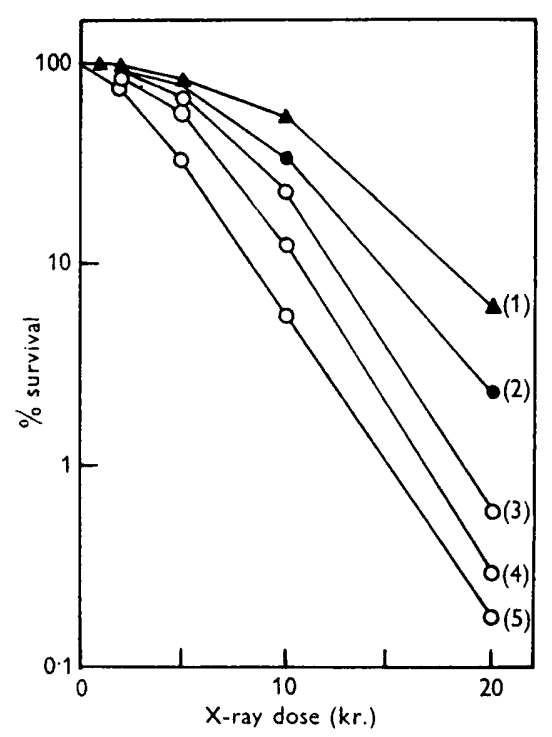

Fig. 1

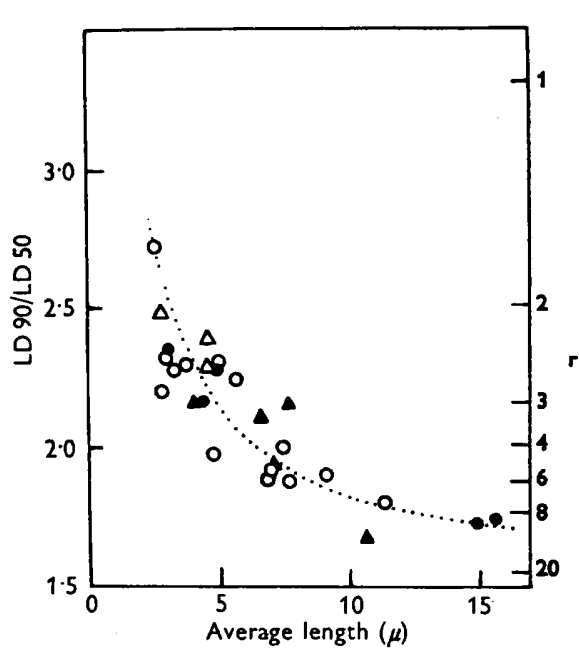

Fig. 2

Fig. 1. X-ray survival curves of Escherichia coli strain $B / r$ of different average lengths. The average cell lengths and culture conditions were: curve $(1), l=11.0 \mu ; 22^{\circ}$, $600 \mathrm{r} . / \mathrm{hr}$.; curve (2), $l=16.1 \mu ; 37^{\circ}, 1000 \mathrm{r} / \mathrm{hr}$.; curve (3), $l=11.8 \mu ; 37^{\circ}$, no gamma radiation; curve (4), $\bar{l}=7 \cdot 3 \mu ; 37^{\circ}$, no gamma radiation; curve (5), $\bar{l}=3 \cdot 1 \mu$; $37^{\circ}$, no gamma radiation.

Fig. 2. The shape of X-ray survival curve of Escherichia coli strain $\mathrm{B} / \mathrm{r}$ as a function of the average length. The shape is expressed in terms of the ratio of the doses for $90 \%$ killing and $50 \%$ killing. $O=$ Cultures at $37^{\circ}$ with no radiation; $O=$ cultures at $37^{\circ}$ with gamma radiation $(1000 \mathrm{r} . / \mathrm{hr}.) ; \Delta=$ cultures at $22^{\circ}$ with no radiation; $\Delta=$ cultures at $\mathbf{2 2}^{\circ}$ with gamma radiation $(600 \mathrm{r}$. $/ \mathrm{hr}$.).

\section{Nuclear staining and $D N A$-ase treatment}

Plate 1, fig. 1 , shows cells from a culture at $22^{\circ}$ at a population density $7 \times 10^{8} / \mathrm{ml}$. grown without gamma irradiation. The cells are very short and have only one or two nuclei. At $37^{\circ}$ and a population density of $10^{7} / \mathrm{ml}$ ( (Pl. 1, fig. 2) the cells are generally much longer and contain several nuclei, mostly grouped in pairs. Under gamma irradiation cells grown at a similar population density at $22^{\circ}\left(\mathrm{Pl}\right.$. 1, fig. 3) and $37^{\circ}$ (Pl. 1, fig. 4) have a completely altered appearance. The regular pattern has largely disappeared and the nuclear material occurs in large masses, often spaced irregularly. In some cases all the nuclear material is gathered into one or two areas and in others there appear to be no nuclei. Many of the shorter cells appear almost unaffected by the radiation.

Photographs of more than 1000 cells at a magnification of $\times \mathbf{7 0 7 0}$ were examined and the number of deeply-stained spots of diameter about $0 \cdot 4 \mu$ (which were assumed to be nuclei) and the cell length type recorded. In many cases spots of this size did not appear clearly separated from each other, and the number of nuclei scored was 
then decided by subjective criteria such as the number of condensations within the deeply stained areas or by the lengths of the stained areas when no condensations were visible. The average lengths of cells containing $1,2,3, \ldots$, nuclei grown under a variety of environmental conditions are shown in Fig. 3. Points for cultures grown at $22^{\circ}$ and $37^{\circ}$, with and without gamma radiation, all lay close to one straight line through the origin. When one selects from the 1150 photographs those in which all nuclei are clearly visible (383) the points obtained also fit the same line.

Although gamma irradiation during growth had a characteristic effect on the appearance of stained preparations some difficulty was encountered in finding simple criteria by which the changed appearance could be expressed quantitatively. To minimize subjective errors it was decided that areas of staining should be scored rather than numbers of individual nuclei. At $37^{\circ}$ significant differences between irradiated and unirradiated cultures were found for: $(a)$ the proportion of cells having no stained areas (Table 1; $P<0.01$ ); $(b)$ the proportion of cells having one central stained area only (Table 1; $P<0.01$ ); $(c)$ the median lengths of cells having between 1 and 6 areas/cell $(P<0 \cdot 01)$. A comparison of preparations of cells treated with and without DNA-ase showed that the enzyme treatment removed most of the stain from the deeply stained areas which had been regarded as nuclei. There seems therefore no reasonable doubt that these were the regions which contained most of the DNA.

Table 1. Proportions and average lengths of Escherichia coli strain $B / r$ in cultures grown with or without gamma irradiation which show: (1) no nuclear stained areas; (2) one such central area only

Continuous cultures at $37^{\circ}$ and population densities between $10^{6}$ and $2 \times 10^{8} / \mathrm{ml}$. Dose rates zero or $1000 \mathrm{r} . / \mathrm{hr}$. Lengths are in $\mathrm{mm}$. on prints at magnification $\times \mathbf{7 0 7 0}$.

\begin{tabular}{|c|c|c|c|c|c|}
\hline \multirow[b]{2}{*}{$\begin{array}{c}\text { Gamma } \\
\text { radiation }\end{array}$} & \multirow[b]{2}{*}{$\begin{array}{l}\text { Total no. } \\
\text { cells } \\
\text { observed }\end{array}$} & \multicolumn{2}{|c|}{$\begin{array}{l}\text { Cells with only one } \\
\text { central stained area }\end{array}$} & \multicolumn{2}{|c|}{$\begin{array}{l}\text { Cells with no } \\
\text { stained areas }\end{array}$} \\
\hline & & No. & $\begin{array}{l}\text { Av. length } \\
(\mu)\end{array}$ & No. & $\begin{array}{c}\text { Av. length } \\
(\mu)\end{array}$ \\
\hline- & 548 & 6 & 17 & $\mathbf{3}$ & 14 \\
\hline+ & 457 & 40 & 22 & 25 & 18 \\
\hline
\end{tabular}

Shrinkage in bacterial preparations and the average cell length/nucleus

It was found that the fixing, staining and mounting of the bacteria caused them to shrink in length and breadth. To find the average spacing of nuclei in a living cell it was therefore necessary to estimate the shrinkage factor. This was done in two ways: (a) by comparing the median values for the distributions of living and stained cells with respect to overall length; $(b)$ by comparing the average lengths of segments into which cells were divided by visible 'waisting' in the living preparation and by incomplete cross-walls in the stained preparations. Consideration of the likely errors leads to the expectation that $(a)$ would yield a falsely high value and (b) a falsely low value. The average values for the factor were: (a) 1.67 $\pm \mathbf{0} \cdot \mathbf{1 6}$; (b) $1 \cdot 26 \pm 0 \cdot 08$. We have adopted the factor $1 \cdot 5$ as the best estimate.

The average distance between nuclei in the photographs, as given by the straight line of Fig. 3, is $0.57 \mathrm{~mm}$.; allowing for shrinkage and magnification the actual distance is therefore $(1.5 \times 0.57) / 7070 \mathrm{~mm}$., i.e. $1 \cdot 21 \mu$. This is sufficiently near 
the rough figure of $1.5 \mu$ for the average length occupied by one radiosensitive unit as found from the data of Fig. 3 to suggest that the numbers of nuclei and radiosensitive units are equal.

\section{Observations on cells treated with lysozyme}

Under the action of lysozyme the cell wall loses its rigidity (Sistrom, 1958) and the remains of cytoplasm within the cell membrane tends to become spherical (= spheroplast) in media of suitable osmotic pressure. Visual observations of Escherichia coli strain $\mathrm{B} / \mathrm{r}$ showed that a high proportion of the shorter cells became spherical after 20-40 min. treatment with the lysozyme solution described (Methods) at room temperature. The average diameter of the spheres appeared to be insensitive to changes in sucrose concentration over the range $0.2-0.5 \mathrm{M}$, but the observations were not sufficiently precise to rule out a slight dependence of size upon sucrose concentration. Cells initially composed of two segments changed to pairs of spheres which often remained in close contact, showing that although the membrane had divided, cell division was not complete. In a $\gamma$-irradiated culture a very long cell which was not segmented was seen to swell simultaneously at two points. One sphere grew more rapidly than the other and burst, whereupon the contents of the rest of the cell were rapidly lost through the open end. This observation suggested

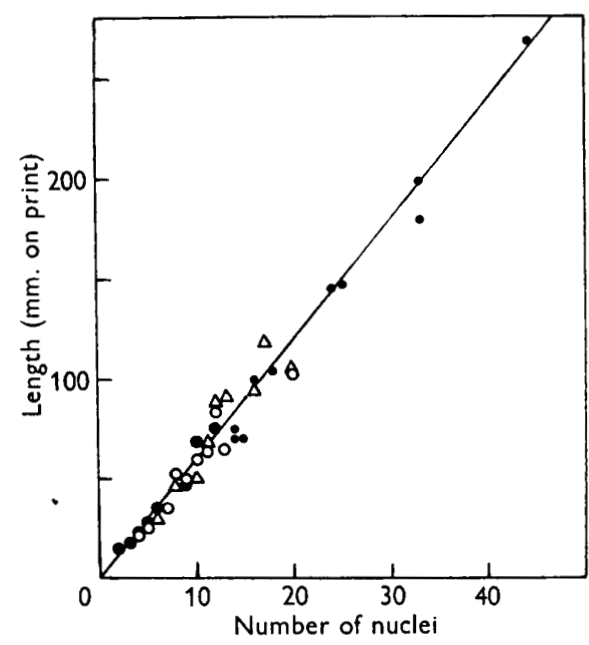

Fig. 3

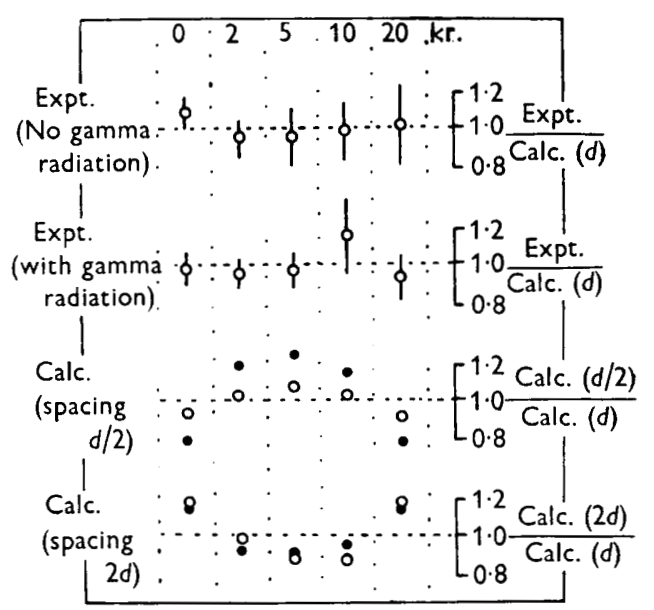

Fig. 4

Fig. 3. The relation between cell length and the number of nuclei for Escherichia coli strain B/r. Data from photographs. Observations for cells with a particular number of nuclei are pooled and the average length plotted. From all cells of unirradiated cultures, $O$; from all cells of $\gamma$-irradiated cultures, $\Delta$; from all cells of all cultures with less than $\mathbf{3}$ observations/point, $\bullet$; from those cells of all cultures in which all nuclei are separately visible,

Fig. 4. Test for systematic deviations of experimental points from calculated survival curves of best fit. At each $\mathbf{X}$-ray dose deviations found in individual experiments were pooled and the mean deviation with its standard error plotted in the upper half of the figure. Data for $\gamma$-irradiated and unirradiated cultures are shown separately. Calculated curves were derived from the corresponding length distributions assuming that each radiosensitive unit occupies a cell length $d(=1.2 \mu)$. The effect of a change in the assumed nuclear spacing by a factor of 2 either way is shown in the lower half of the figure for typical populations of short $(O)$ and long $(O)$ average length. 
that the absence of constrictions of the cell wall was probably associated with absence of transverse septa.

Measurements on a large number of cells from one culture showed that the distributions with respect to volume before and after exposure to lysozyme were very similar except at large volumes, where the discrepancy was consistent with a relatively high probability of bursting. The average cell length, the average segment length and the average length of a rod of the same diameter as a normal cell and equal in volume to the average type, are recorded in Table 2 for three continuous cultures grown from the same parent culture and operated simultaneously. The close agreement between the figures in the last two columns implies that when a segment becomes spherical the change in volume must be relatively small.

Table 2. Sizes of whole cells, segments and the osmotically-sensitive spheroplasts derived from them by lysozyme treatment

For comparison purposes the average volume of the spheroplasts is expressed in terms of the length of a rod-shaped cell having the same volume.

\begin{tabular}{|c|c|c|c|c|c|}
\hline \multicolumn{3}{|c|}{ Cultural conditions } & \multirow{2}{*}{$\begin{array}{c}\text { Average } \\
\text { cell } \\
\text { length } \\
(\mu)\end{array}$} & \multirow{2}{*}{$\begin{array}{c}\text { Average } \\
\text { segment } \\
\text { length } \\
(\mu)\end{array}$} & \multirow{2}{*}{$\begin{array}{l}\text { Equivalent } \\
\text { average } \\
\text { length for } \\
\text { spheroplasts } \\
(\mu)\end{array}$} \\
\hline Temp. & $\begin{array}{c}\text { Population } \\
\text { density }\end{array}$ & $\begin{array}{c}\text { Gamma } \\
\text { radiation }\end{array}$ & & & \\
\hline $23^{\circ}$ & $4-10^{8} / \mathrm{ml}$ & 一 & $2 \cdot 7$ & $\mathbf{2 \cdot 0}$ & $2 \cdot 2$ \\
\hline $23^{\circ}$ & $10^{7} / \mathrm{ml}$ & 600 r./hr. & $9 \cdot 5$ & $7 \cdot 6$ & $6 \cdot 4$ \\
\hline $37^{\circ}$ & $10^{7} / \mathrm{ml}$ & - & $5 \cdot 7$ & $3 \cdot 7$ & $4 \cdot 1$ \\
\hline
\end{tabular}

Test of the hypothesis that the number of radiosensitive units/cell is equal to the number of nuclei

Although the evidence for the equality of the numbers of nuclei and radiosensitive units presented above is sufficient to justify it as a working hypothesis, a more searching test is desirable, for the following reasons. The data of Fig. 2 are concerned with survival in the range 10-100\%, which constitutes only part of the available experimental information. Also the relation between the ratio LD90/LD50 and the number of radiosensitive units/cell shown in Fig. 2 applies strictly only to a uniform population, whereas our cultures were markedly not uniform with respect to cell length (Maclean \& Munson, 1961) and therefore not uniform with respect to the number of units/cell. A direct estimate of the average number of radiosensitive units/cell from the survival data could not be made by the method of Atwood \& Norman (1949) because the numbers of nuclei/cell had distributions which deviated widely from a Poisson distribution. We have therefore tested our hypotheses by comparing the shape of the experimental survival curve for each culture with the corresponding shape of the calculated curve and looking for evidence of systematic discrepancies between them.

To calculate the survival curve for each culture it was first necessary to determine the distribution of the number of nuclei/cell. For each cell of length $l$ the number of nuclei was taken as the integer nearest to $l / d$, where $d$ is the average nuclear spacing $(1 \cdot 21 \mu)$. If for each nucleus there were one unit of radiosensitivity $\lambda$ and there were $n_{r}$ cells with $r$ nuclei in a sample of $N$ cells, the surviving fraction would be

$$
S=\sum^{r} n_{r} S_{r} / N
$$

where $S_{r}$ is given by equation (1) and the summation is over all observed values of $r$. 
Values of $S$ have been calculated for a number of values of $\lambda D$ in equation (2) and they have been fitted to the observed surviving fractions ${ }_{0} S$ at different doses $D$ in the following way. $\log _{c} S$ has been plotted against $\log D$ on one piece of paper and $\log S$ against $\log \lambda D$ on a separate piece of transparent paper. The two superimposed sets of points were then made to lie as nearly as possible on the same curve by a shift of one set parallel to the $\log D$ axis. The magnitude of this shift was a measure of $\log \lambda$, since $\log \lambda D=\log \lambda+\log D$. The value of $\log \lambda$ for the best fit was found by the method of least squares. For cultures grown in the absence of gamma radiation a weight proportional to the square root of the number $p_{i}$ of surviving cells (colonies) counted was assigned to each experimental point (the mean variance of replicate counts was $\left.3 p_{i}\right)$ and the value of $\sum^{i}\left(\log _{0} S-\log S\right)^{2}$ found for different assumed values of $\lambda$. The minimum value of this sum, which corresponded to the best value of $\lambda$, was found by graphical interpolation. For cultures grown with gamma irradiation the variance of replicate counts increased with dose from $2 p_{i}$ at zero dose to $9 p_{i}$ at $20 \mathrm{kr}$. The weights assigned to points for different doses were adjusted accordingly and the rest of the fitting procedure carried out as already described.

If there were a systematic discrepancy between the shapes of the calculated curves of best fit and the observed ones, this would be expected to show up when the results of all experiments at each dose were pooled and the mean of the ratios ${ }_{0} S / S$ plotted as a function of dose; Fig. 4 shows the results of this test. For 18 cultures grown in the absence of gamma radiation and for 9 grown under gamma irradiation the means of the ratios differed from unity by less than their standard deviations, indicating no significant discrepancy at any dose.

Some idea of the limits within which the average 'target' spacing could be fixed by the survival data alone was found by calculating surviving fractions for typical long (11 $\mu$ ) and short $(2.5 \mu)$ populations with assumed 'target' spacings of $2 \times 1.2 \mu$ and $0.5 \times 1.2 \mu$. These fractions were then compared with those calculated for a spacing of $1.2 \mu$; the results are shown in the lower half of Fig. 4 . In both cases the deviations from unity exceed the mean experimental ones, indicating that a spacing of $1.2 \mu$ fits the experimental data better than either of the alternative spacings.

\section{Radiosensitivity of the targets}

Having found the calculated curve of the best fit for each culture, the value of $\lambda$ followed at once. For cultures grown in the absence of gamma radiation at $\mathbf{2 2}^{\circ}$ and $37^{\circ}$, the average value of $\lambda$ was $0 \cdot 349 \pm 0 \cdot 025$, whilst for cultures grown under gamma irradiation at $600 \mathrm{r}$. $/ \mathrm{hr}$. at $22^{\circ}$, and $1000 \mathrm{r}$. $/ \mathrm{hr}$. at $37^{\circ}$, it was $0 \cdot 289 \pm 0 \cdot 040$. These values are significantly different $(P<0 \cdot 01)$.

\section{Lengths of bacterial segments}

The number of segments into which each living cell was divided by visible 'waists' was noted when its length was measured under the microscope. The proportion of the population with $1,2,3, \ldots$, segments varied from culture to culture, but the variations were not large and no correlation of the proportions with cultural conditions was evident. The length of the shortest cells in a culture was almost 
Table 3. Sizes of cell segments under different cultural conditions Average lengths are given for the whole population and for those cells which comprise the shortest $2 \%$ of the population.

\begin{tabular}{|c|c|c|}
\hline \multicolumn{3}{|c|}{ Cultural conditions } \\
\hline Temp. & $\begin{array}{c}\text { Population } \\
\text { density } \\
\text { (ml.) }\end{array}$ & $\begin{array}{c}\text { Gamma } \\
\text { radiation }\end{array}$ \\
\hline $23^{\circ}$ & $10^{7}-10^{8}$ & - \\
\hline $23^{\circ}$ & $10^{7}-10^{8}$ & + \\
\hline $37^{\circ}$ & $10^{7}$ & - \\
\hline $37^{\circ}$ & $10^{7}$ & + \\
\hline $37^{\circ}$ & $4 \times 10^{8}$ & - \\
\hline $37^{\circ}$ & $4 \times 10^{8}$ & + \\
\hline
\end{tabular}

Average segment lengths for cells composed of

independent of the cultural conditions, in contrast with the large dependence shown by the average length. This is illustrated in Table 3 in which data for cultures grown under similar conditions have been pooled. Results for cells with one segment and two segments are separately classified, the figures for the shortest cells being the average for 3-5 cells which comprised the shortest $2 \%$ of each class. Although the choice of the fraction $2 \%$ was arbitrary, these results show that the smallest bacteria may be presumed to have lengths in the range $1 \cdot 5-2 \mu$ at 'birth'.

\section{DISCUSSION}

Brownell (1955) reported an approximate equality between the average number of radiosensitive units/cell and the average number of nuclei/cell for comparatively short cells (1-4 nuclei/cell) of Escherichia coli strain B/r from batch cultures in minimal medium. The values of radiosensitivity given by Brownell's data, namely, $0 \cdot 45$ and $0 \cdot 50$, may be compared with our value of $0 \cdot 35$.

For cultures growing under $\gamma$-rays the doses received by cells"during one generation time were in the region of $10^{3} \mathrm{r}$., so only a very small \% of cells should have failed to form colonies when plated (Fig. 1). Although the measured proportions of viable cells were not at variance with this expectation, the fact that the growth rate was not significantly decreased by $\gamma$-irradiation (Maclean \& Munson, 1961) was the best evidence that radiation damage was not serious for the culture as a whole.

Our observations on cells treated with lysozyme indicate that one membrane normally encloses the contents of one segment and that cell division does not always take place as soon as the division of the cell membrane is complete. If there are transverse septa within segments they must be relatively weak, otherwise their presence would have been evident during the change of segment shape from rod to sphere.

It has been shown that the aggregation of chromatinic material in bacteria exposed to damaging agents such as ultraviolet radiation is dependent upon the salt concentration of the suspending medium (Whitfield \& Murray, 1956). There are, however, diverse views about the significance of nuclear aggregation (Williams, 1959) so it would be premature to attempt to explain the role of gamma radiation in producing nuclear aggregation in Escherichia coli strain B/r. Whatever its cause, 
nuclear aggregation in the $\gamma$-irradiated cells appeared to increase rather than to decrease the chance of surviving $\mathbf{X}$-irradiation, so it may be presumed that undamaged nuclei can extricate themselves and initiate cell division. The absence of any transverse membrane within a segment would permit rapid diffusion of materials within the membrane and also perhaps a re-organization of aggregated nuclear material after the manner of fusion nuclei as envisaged by Bisset (1948).

The relative constancy in the length of the shortest segments of the living cells, grown under a variety of conditions (Table 3), shows that there was a preferred minimum length and that some cells of this length always arose despite a general inhibition of cell division in the population as a whole. The close correspondence between this minimum length (about $1.5 \mu$ ), the length/nucleus given by staining $(1 \cdot 2 \mu)$ and the length occupied by one radiosensitive unit (1-1.5 $\mu)$ is strong evidence that a radiosensitive unit contains one nucleus and is functionally almost identical with the smallest cell of Escherichia coli strain B/r which can exist. In order that it should function independently each unit must have at least one nucleus and the average one must contain less than two; otherwise the experimental and calculated survival data could not be reconciled.

The uniformity in the spacing of nuclei along cells of all lengths shows that nuclear division proceeded in step with cytoplasmic growth at a constant rate over a wide range of population densities at $37^{\circ}$ (compare Katchman, Spoerl \& Smith, 1955). On the other hand, different population densities had a marked effect on cell division, one pair of transverse membranes being formed on the average for each pair of nuclei at high population densities and for each 4 or 5 pairs of nuclei at low population densities. Thus the 'terminal stage' of cell division, namely, the laying down of transverse cell membranes followed by segmentation and separation of the daughter cells was much more sensitive to environmental changes than was the rate of production of nuclear and cytoplasmic materials. The appearance of 'giants' among X-irradiated mammalian cells (Puck \& Marcus, 1956) implies a similar inhibition of cell division. Moreover, with Escherichia coli strain $\mathbf{B} / \mathbf{r}$ the wide range of cell lengths within one culture indicates that individual bacteria differ from each other in respect of cell division, although for the culture as a whole the number of nuclei produced/cross-wall has a definite characteristic value. This characteristic value is dependent upon the three environmental factors; temperature, population density and gamma-radiation dose rate. Since the effect of one factor can be modified by either of the others, each probably affects the same process (Maclean \& Munson, 1961). The evidence provided by the present experiments leads us to conclude that this process is the terminal stage of cell division and that it can be inhibited almost completely without quantitatively affecting the continued multiplication of other cellular components. For an individual cell, completion of division may be simply a matter of random chance, although statistically one could assign to it a certain probability/unit time. According to this view no fundamental distinction can be made between cells of different lengths in the same culture.

We gratefully acknowledge the helpful advice of Dr K. A. Bisset on the technique of nuclear staining. We are also indebted to Miss T. Alper and Dr N. E. Gillies for allowing us to see their experimental data about 'restoration' before publication, and to Miss P. A. Jeffery for very able technical assistance. 


\section{REFERENCES}

Alper, T. \& Gillies, N. E. (1960). The relationship between growth and survival after irradiation of Escherichia coli strain B and two resistant mutants. J. gen. Microbiol. 22, 113.

Atwood, K. C. \& Nonman, A. (1949). On the interpretation of multi-hit survival curves. Proc. nat. Acad. Sci. Wash. 35, 698.

Bernheimer, A. W. \& Steele, J. M. (1955). Ribonuclease and ribonuclease inhibitors among higher plants. Proc. Soc. exp. Biol., N.Y. 89, 123.

Bisset, K. A. (1948). Nuclear reorganisation in non-sporing bacteria. J. Hyg., Camb. 46, 173.

Brownelu, A. S. (1955). The effect of physiological and morphological changes on the radiation sensitivity of Escherichia coli. University of California Radiation Laboratory Report (unclassified) UCRL 3055.

Katchman, D. J., Spoerl, E. \& Smith, H. E. (1955). Effect of cell division inhibition on phosphorus metabolism of Escherichia coli. Science, 121, 97.

LEA, D. E. (1946). Actions of Radiations on Living Cells. Cambridge University Press.

LEDERBERG, J. (1950). Isolation and characterization of biochemical mutants of bacteria Meth. med. Res. 3, 5.

Maclean, F. I. \& Munson, R. J. (1961). Some environmental factors affecting the length of Escherichia coli in continuous cultures. J. gen. Microbiol. 25,

MAHLER, H. R. \& Fraser, D. (1956). Reproduction of bacteriophage T3 in protoplasts of Escherichia coli strain B. Biochim. Biophys. Acta, 22, 197.

McDonald, M. R. (1955). In Methods in Enzymology, Vol. 2, p. 427. Ed. S. Colowick \& N. A. Kaplan. New York: Academic Press.

Puck, T. T. \& Marcus, P. I. (1956). Action of X-rays on mammalian cells. J. exp. Med. $103,653$.

Roninow, C. F. (1944). Cytological observations on Bact. coli, Proteus vulgaris and various aerobic spore-forming bacteria with special reference to the nuclear structures. $J$. Hyg., Camb. 43, 413.

Sistrom, W. R. (1958). On the physical state of intracellularly accumulated substrates of $\beta$-galactose permease. Biochim. Biophys. Acta, 29, 579.

Stapleton, G. E., Billen, D. \& Hollaender, A. (1953). Recovery of X-irradiated bacteria at suboptimal incubation temperatures. J. cell. comp. Physiol. 41, 345.

Whitfield, J. F. \& Murray, R. C. E. (1956). The effect of ionic environment on the chromatin structures of bacteria. Canad. J. Microbiol. 2, 245.

Williams, M. A. (1959). Chromatin patterns in Spirillum anulus. J. gen. Microbiol. 21, 109.

\section{EXPLANATION OF PLATE 1}

Escherichia coli strain B/r stained by HCl-Giemsa method and mounted in Canada balsam. Magnification, $\times 2520$.

Fig. 1. Cultivation at $22^{\circ}$ at population density $7 \times 10^{8} / \mathrm{ml}$.; no gamma radiation. Cells had one or two nuclei only.

Fig. 2. Cultivated at $37^{\circ}$ at population density $10^{7}$; no gamma radiation. Cells with 4 and 8 nuclei were most common, nuclei being usually in close pairs or groups of four.

Fig. 3. Cultivated at $22^{\circ}$ at population density $2 \times 10^{7} / \mathrm{ml}$. under gamma irradiation at $600 \mathrm{r}$. $/ \mathrm{hr}$. Nuclear pattern much less regular than in fig. 2; there is some aggregation.

Fig. 4. Cultivated at $37^{\circ}$ at population density $4 \times 10^{8} / \mathrm{ml}$. under gamma irradiation at $1000 \mathrm{r}$. $/ \mathrm{hr}$ Nuclear pattern in longer cells very irregular; gross aggregation. Several cells appear to have no nuclei. 
Journal of General Microbiology, Vol. 25, No. 1

Plate 1

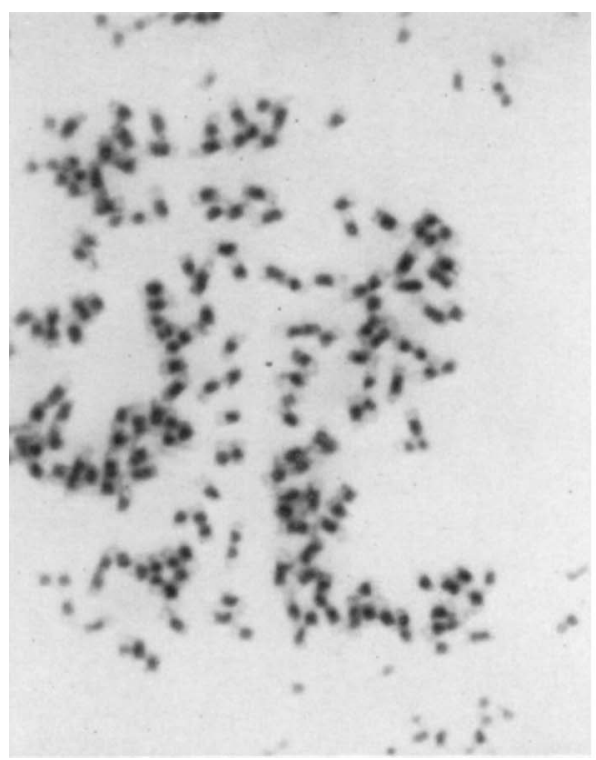

Fig. 1

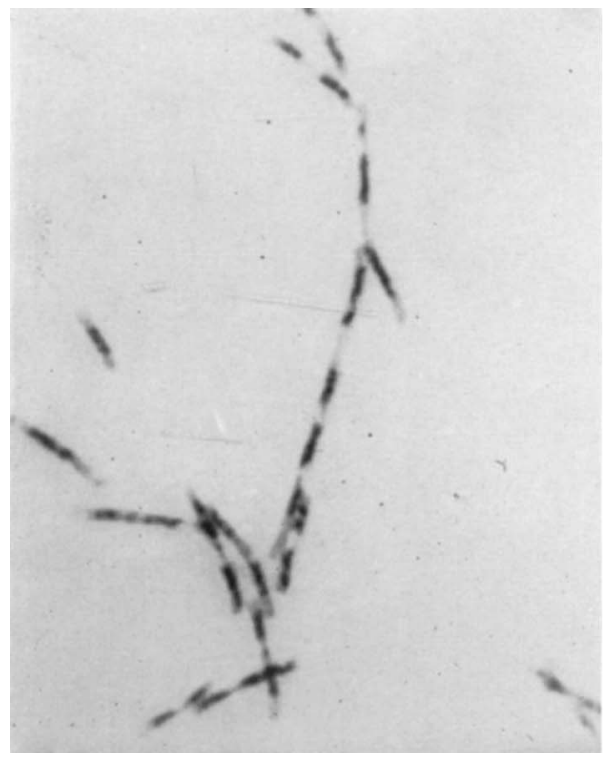

Fig. 3

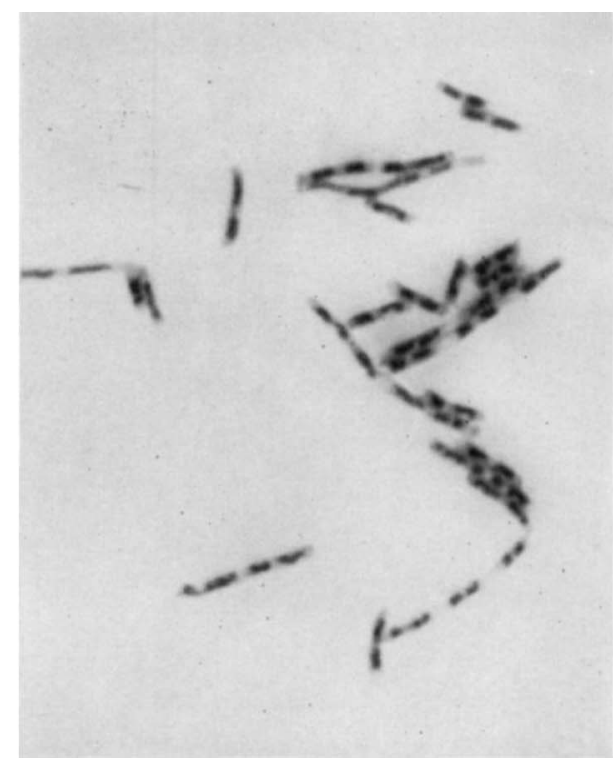

Fig. 2

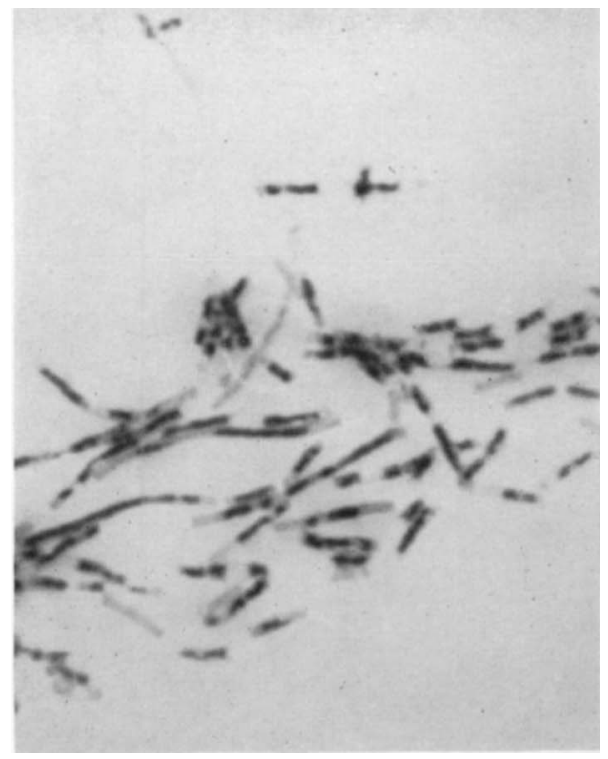

Fig. 4 